\title{
Engagement during pandemic teaching: Report of the EAAI-21 Panel on Teaching Online and Blended AI Courses
}

\section{Michael Wollowski}

Rose-Hulman Institute of Technology, Terre Haute, Indiana, USA

\section{Correspondence}

Michael Wollowski, Rose-Hulman Institute of Technology, 5500 Wabash Ave, Terre Haute, IN 47803, USA. Email:wollowsk@rose-hulman.edu

\begin{abstract}
Three panelists, Ashok Goel, Ansaf Salleb-Aouissi and Mehran Sahami explain some of the tools and techniques they used to keep their students engaged during virtual instruction. The techniques include the desire to take one's passion for the learning materials to the virtual classroom, to ensure teacher presence, provide for cognitive engagement with the subject and facilitate social interactions. Finally, we learn about tools used to manage a large online course so as to move the many active learning exercises to the virtual classroom.
\end{abstract}

In this panel, $\mathrm{AI}$ faculty with experience teaching online and blended classes were asked to share their experiences teaching online classes. The panel was composed of Ashok Goel, Georgia Institute of Technology, Ansaf SallebAouissi, Columbia University and Mehran Sahami, Stanford University. The panelists were asked to describe which tools and methods work well to help instructors engage and bond with students online. They were furthermore asked to share their insights into which components of a course can be done best online and which ones are best accomplished in person. The panel took place as part of the 2021 Symposium on Educational Advances of AI, which was collocated with AAAI-21. The panel was attended by about 55 people and it included a vigorous Q/A portion.

Ansaf suggested that we take our passion for the materials and our compassion for our students with us into cyberspace. She teaches an AI course to about 150-200 students in a synchronous fashion. Ansaf addressed some basics of online teaching. In order to increase ease of navigation, she suggested to limit the number of technologies. She uses the Notability app to annotate slides, Canvas, to manage the course, Piazza for student questions as well as Zoom. Ansaf found that students are less shy about asking questions while online to the extent that the number of questions became overwhelming. She engaged her TAs to answer them. A main point Ansaf made was to make online class special, something students look forward to.
To that end, she varies the learning materials, using short videos, demos and apps. She additionally posts thoughtprovoking articles for post-class discussion and engaged experts to give a few guest lectures. She asked her TAs to hold weekly recitations, which are recorded and posted. Since the TAs are closer in age to her students, these sessions are well received. Ansaf implored us to show compassion for our students during these difficult times. She uses a clever submission policy in which students earn points for early submission, but loose points for late submissions and have a window of several days in between. Ansaf ended her delightful presentation by suggesting bringing a smile to class and to stay for some time after class so as to relate to your students that you are present.

Ashok focused on three aspects of his course that are designed to increase student engagement: (i) teacher presence, (ii) cognitive engagement and (iii) social interaction. All of them use AI in one way or other. Ashok teaches an online course on "Knowledge-Based AI." For a detailed write-up of that course, see Goel and Joyner (2017).

Ashok and his team created a concept inventory of 150 concepts and skills as well as typical misconceptions about them. Throughout the course, each concept is covered in about 6-8 min. During the presentation of a concept, an automated tutor monitors a student's performance, in particular when answering questions. The tutor gives positive reinforcement or offers clarification when it recognizes 
a misconception. Uncommon misconceptions are clarified by human teaching assistants. His students find this instant feedback engaging.

Ashok's course has a significant project-based learning component. The project centers on developing an AI agent that is capable of solving Ravens progressive matrices tests as well as humans can, see Ravens (1958). His students find those problems as well as developing software that can solve them addictive. When developing the software, his students introspect and attempt to observe how they themselves solve those problems and use those insights to improve their software. Ashok relates that these assignments account for high cognitive engagement with the learning materials and the course subject. Another instance of cognitive engagement occurs through the use of Jill Watson, an AI agent that answers student questions. Ashok mentioned that during one offering of his class, there were 11,000 contributions on the Piazza board associated with his class. To answer some of the questions posed there, he and his team built Jill Watson, an AI agent that can answer student questions, see Goel (2016.) Currently, she can answer $95 \%$ of the questions with $85 \%$ precision. His students find their interactions with a real AI tool fascinating.

Students in Ashok's course are asked to introduce themselves in writing. He and his team developed an NLP agent called SAMI that automatically greets students as well as makes targeted introductions based on location and shared interests. During the discussion portion, Ashok mentioned that at some point, he will be able to make the agents described above available to a broader audience. However, the data that they ingest will have to be collected and curated for the subject and level of course in which it is deployed.

Mehran teaches a course that is very interactive and has numerous active learning activities, including panels with invited guests, small group discussion sections and think-pair-share activities. He explained how he captured that interactivity when he had to move this course online. Mehran teaches a course on "Ethics, Public Policy and Technological Change" together with colleagues from Philosophy and Political Science, to about 300 students.

Mehran explained how he managed the basics of interaction with his students so as to support active learning activities. He uses a separate, private channel of communication with his teaching assistants. To provide for a smooth flow of instruction, students are asked to pose questions to his teaching assistants. His TAs answer questions; additionally, they are empowered to elevate questions to the instructor, in particular those that center around repeatedly asked questions. He monitors this private communication channel and thereby can seamlessly integrate answers or follow-up materials into the flow of the class.
Mehran and his team, including a colleague from $\mathrm{A} / \mathrm{V}$ developed a rather sophisticated system to support an interactive learning experience. At the start of the term, each student is assignment to one of seven panel groups. To allow for a more dynamic exchange, the instructors directly interact only with the 30-40 students of the "empaneled" students. They use a separate Zoom session to facilitate those interaction. This session is broadcast to all other students. In order to manage student to TA interaction, the remaining students are split into two separate Zoom sessions. To ensure equal participation, Mehran and his colleagues cycle through the panel groups every class session.

Mehran and his TAs offer different types of online office hours. Some office hours are individual, to allow private discussions and some are open to all students who join simultaneously. He uses the www.nooks.in platform that enables his students to form subgroups around similar topics, while they are waiting their turn for office hours.

During the discussion portion of the panel, Mehran summed up a key effect of the grand experiment of sudden online teaching: It makes us think about interaction and how to best facilitate it.

\section{REFERENCES}

Goel, A., and D. Joyner. 2017. "Using AI to Teach AI." AI Magazine 38(2): 48-59.

Goel, A. 2016. A Teaching Assistant Named Jill Watson. TedX talk located at: https://www.youtube.com/watch/WbCguICyfTA

Ravens, J.C. 1958. Standard Progressive Matrices. London: H. K. Lewis \& Co. Ltd.

\section{AUTHOR BIOGRAPHY}

Michael Wollowski is a Professor of Computer Science at Rose-Hulman Institute of Technology. He received his $\mathrm{PhD}$. from Indiana University under the direction of Jon Barwise. Michael is an associate editor for AI Magazine and the editor in charge of the AI Education column. His current research focuses on AI education and human-robot collaboration.

How to cite this article: Wollowski, M. 2021.

"Engagement during pandemic teaching: Report of the EAAI-21 Panel on Teaching Online and Blended AI Courses." AI Magazine 42: 77-78.

https://doi.org/10.1609/aaai.12009 